\title{
BHP mine water management: an integrated approach to manage risk and optimise resource value
}

\author{
C Ahumada Calderon BHP, Australia
}

\begin{abstract}
BHP owns and operates large and long life assets with diverse challenges and opportunities that require long-term business plans to manage risk and maximise the resource value. Mine water management plays a fundamental role in the business plan, as a key enabler or as a main constraint in the mine plan. A defined integrated approach of mine water management needs to be embedded in the core business processes as business planning, risk management and into operational processes.

BHP's approach to define an adequate mine water management plan needs to consider a diverse range of components such as risk management appetite, strategic, planning and operational plans, data, analysis and knowledge to assess the uncertainty. Integrated risk assessments that include mine planning, geotechnical and water risks are important steps that BHP is improving to give flexibility to our mine plans and to define effective controls at different levels. Implementing strategic and operational plans, and incorporating and aligning them into the mine planning processes will ensure water-related decisions can be made with the technical basis at the time required. Improvements of technical characterisation of hydrogeological, water management and geotechnical that have been informed by the dynamic monitoring networks, data acquisition and technology implemented have been fundamental to evolve the conceptualisations and models that inform geotechnical design and mine plans. Understanding and preparedness for multidisciplinary technical uncertainty is something that BHP is also addressing, focusing on improving the skills to assess this and the data required.
\end{abstract}

A mine water management integrated approach will help us to achieve adequate mine water management to inform slope stability, mine planning and operations to make the right decisions, manage risks and optimise resource value.

Keywords: mine water management, business planning, risk management, resource value, uncertainty

\section{Introduction}

Water is a vital shared resource. It is essential to life and plays a spiritual, cultural, recreational, ecological and economic role in every landscape.

As a global resource company, our shared water management responsibility is to understand the technical fundamentals, as characterised at our operations, and build knowledge as to how hydrological and hydrogeological changes can affect our surrounding environments. By incorporating this water knowledge and information into our formal planning and operating processes, we can prioritise our activities based on risk.

We are among the world's key producers of major commodities, including iron ore, coal and copper. We also have substantial interests in oil, gas and nickel. We are a global company with assets primarily in Australia, South America and North America. We own and operate Tier 1 assets that have a large and long life and that require long-term planning to achieve and maximise the value of mineral resources.

Mine water management is a key enabler for our operations and activities such as mine dewatering, mine depressurisation and pit void water management and is an essential activity which informs our mine plans and maximises value during operations. BHP recognises that the proactive management of hydrological and hydrogeological conditions is directly related to causal factors of impacts to mine production, geotechnical engineering and safety. 
In recognition of the importance of fundamental technical considerations, BHP has developed a Technical Centre of Excellence (TCOE) to support the integration of technical disciplines related to geoscience and resource engineering. The objective of the TCOE is to deliver enhancements in technical tools, set and manage BHP technical standards, and share best practice and lessons between our operations and assets and with other industry bodies and companies.

Historically, mine water management has impacted BHP across all commodities constraining mine plans and production. Dewatering and pit voids have changed mine plans because they have not been considered properly in the planning and operational plans, or because water management cannot adapt fast enough to mine plan change. In our Western Australian iron ore operations, mine dewatering limited the rate of mining and location; in Chile at our copper operations, depressurisation resulted in shallower slopes and continuous mine re-design. Flooded pit voids in our Queensland coal operations constrained mine plans development optionality.

Like the majority of slope water management issues, these cannot be resolved quickly. Sustainable options require not only long lead proactive planning and integrated technical work but also education and capability building. For this reason, integrating slope water management into the business planning process and the operational process is essential to meet our objectives.

\section{$2 \quad$ Understanding why mine water management}

BHP's approach to mine water management for our operations differs according to climate, mining resource and method, and geography. In many cases, water management is a significant factor in allowing production, managing geotechnical risks and delivering sustainable groundwater supplies.

Although our operations may have different water-related risks, challenges and opportunities, early integrated mine and geotechnical planning and long lead time investment in water infrastructure ensure proper controls are in place to adequately manage the risks.

Mine water management at our operations needs to consider core production activities like mine dewatering, pit slope depressurisation, pit voids management, water supply and surplus water management.

In general, mine water management present risks and opportunities across all assets in BHP. For the purposes of what we are outlining, the focus will be on three key locations where this is a key enabler for production and geotechnical engineering: our coal operations in Queensland, Australia; our Escondida copper mine in northern Chile; and our Western Australia Iron Ore (WAIO) operations in Australia (Figure 1).
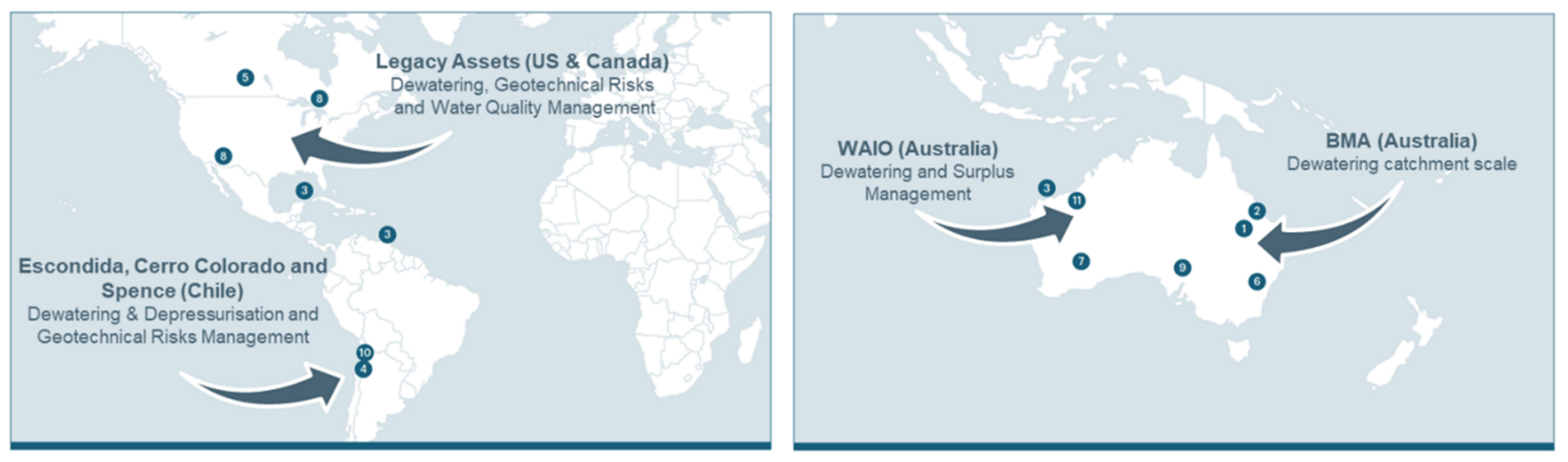

Figure 1 Main mine water management locations across BHP operations

Our overall approach to proactive water management incorporates hydrological and hydrogeological considerations into BHP's fundamental business processes. This allows for an optimised mine plan to consider water as a deliberate input with specific planning objectives. These objectives usually enable one or more of the following production outcomes:

- Dry operating conditions, to enable mining and provide a safe operating condition. 
- Dry blasting conditions, to reduce blast products.

- Improved geotechnical ground control by depressurisation/dewatering of pit slopes, to reduce risk of pit slope failure.

- Reduced in situ ore moisture content conditions (as a bulk rock \%) to support material handling requirements.

- Increased mine development flexibility (prepare for various mine development schedule scenarios) to reduce pit water being a constraint to mining.

- Operational process water supply.

Following the development of a water strategy, the mine water management and planning objectives can be determined and built around achieving flexibility in mine planning outcomes and to accommodate the inherent uncertainty in climatic and hydrogeological conditions. For example, dewatering in WAIO is a critical enabler to access ore below the watertable. As around 30\% of the current operation is located below watertable, up to $200-250 \mathrm{ML} / \mathrm{d}$ of groundwater must be pumped to lower the watertable in advance of mining to access the ore. This drives the need for integrated planning between hydrogeology, mine design, engineering and environmental approvals.

The development and integration of the dewatering strategy has become an integral part of the mine design, planning and the geotechnical risk and controls. The strategy recognises that proactive dewatering requires decisions to be made $2-10$ years prior to mining and during this period, mine plans do change. With these changes, a degree of flexibility is needed in the dewatering design whether it is access to new mining areas or increased mining rates to access ore of higher quality and value. The strategic approach aligns the degree of flexibility with risk tolerance and assigns planning priorities and capital costs based on the degree of agreed flexibility.

In addition to moving large volumes of water, mine groundwater management is also a causal factor for geotechnical risks at a number of our operations. The stability of pit slopes and tailings storage facilities relies on hydrogeological characterisation and the development of drainage and seepage control methods to lower the risks of failure and contamination. For example, at Escondida in Chile, depressurisation is required to maintain stable slopes and reduce the amount of waste movement through steepening slopes. These slopes could be up to $600 \mathrm{~m}$ high or more with failure mechanisms relating to both rock mass and structure. For these particular failure mechanisms, achieving a reduction in pore pressures becomes an important design consideration.

\section{BHP mine water management approach}

At BHP, mine water management is embedded within our core business processes of corporate alignment planning (CAP) and risk management. The CAP process creates alignment across the organisation to guide the development of plans, targets and budget to which facilitate and help deliver our strategy. In addition, the planning process allows full exposure and prioritisation of the water-related risk and the aggregate impact from cumulative risks. By embedding mine water planning in this process we are enabled to make proper decisions at the right time which is a key driver for slope water management.

The approach to mine water management in our operations is through a multidisciplinary process that is categorised into four major streams:

1. Risk management.

2. Strategic, planning and operations.

3. Data and information.

4. Improve technical knowledge and an understanding of uncertainty.

Currently, BHP is working to improve on these streams across all our operations (Figure 2). 


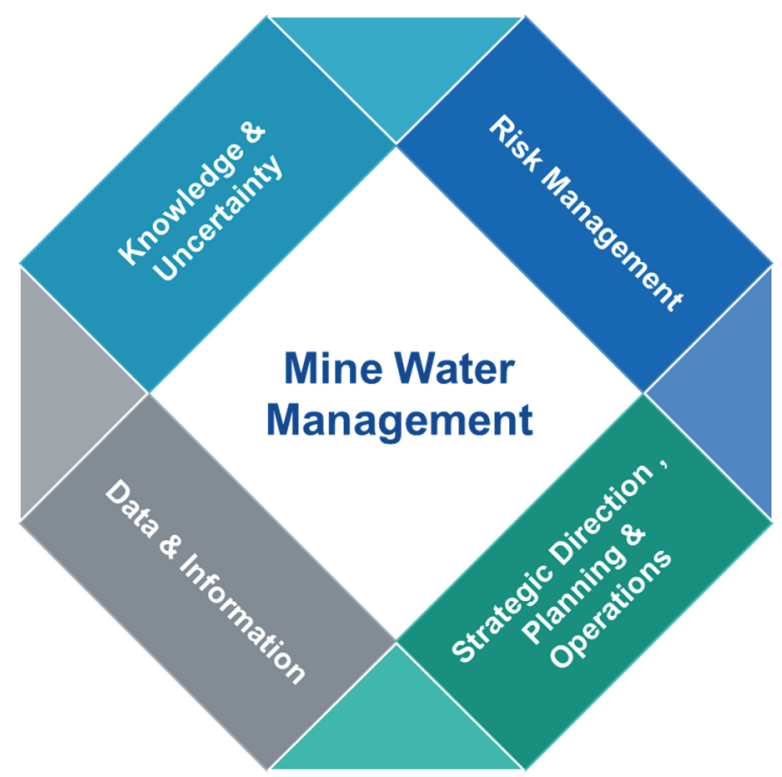

Figure 2 Mine water management process

\subsection{Risk management}

Due to the nature and location of our operations, we are exposed to a broad spectrum of water-related risks. Water risk identification as an integrated part of our mine and business planning ensures effective controls and treatments are adopted, particularly for the material risks and the core slope water management interdependencies between planning and operational activities through the mine life.

Risk management is one of our central management processes requiring operation to analyse risks through the perspectives of safety, environment, reputation, legal and financial impacts. This follows the guidelines defined in BHP 'Our Requirements Risk Management'. Risk process has a series of steps that includes identification, assessment and the management of risks aligned to the ISO 31000 guidelines (International Organization for Standardization 2018). Not all risks are the same or have the same characteristics, and for this reason, risk has been categorised into strategic, current and emerging risks. As part of this process, we define the nature and extent of risk we are willing to take in pursuit of our production objectives. This is our 'risk appetite'.

Water risks and geotechnical risk appetite definition is fundamental for driving our mine water risk management and controls. In general, slope water management risks are associated with ground failure and geotechnical stability, however, it is also important to consider the loss of value due to no optimisation of resources. This is the case for our Tier 1 assets which have had significant investments into mining methods, flow and value chain, and been in operations for many decades. When these operations were established, it is fair to say that even though in many cases mine water management was recognised as an important enabler and also a resource which needs to be managed, it didn't largely determine the mine designs or the approach to mineral processing. Along the way though, we have found that mine water management is significant and an extremely important input and variable to optimise mine plans, geotechnical design and value optimisation.

Some of the risks associated with mine water management at BHP are identified in Table 1. 
Table 1 Mine water management related risks

\begin{tabular}{|c|c|c|}
\hline Type & Causes & Potential impacts \\
\hline Planning & $\begin{array}{l}\text { Ineffective strategic, planning and } \\
\text { management of groundwater and surface } \\
\text { water ingress to operations }\end{array}$ & $\begin{array}{l}\text { Erosion of value, failure to } \\
\text { maximise the value of the } \\
\text { mineral resource }\end{array}$ \\
\hline \multirow[t]{2}{*}{$\begin{array}{l}\text { Production and } \\
\text { operational }\end{array}$} & $\begin{array}{l}\text { Mine designs fail to consider risk appetite } \\
\text { and the appropriate range of possible } \\
\text { outcomes, planning and technical } \\
\text { uncertainty, and climate variability }\end{array}$ & $\begin{array}{l}\text { Non-compliance to business } \\
\text { plan, unsafe operating } \\
\text { conditions, increased operational } \\
\text { costs, and the full extent of the } \\
\text { resource cannot be extracted }\end{array}$ \\
\hline & $\begin{array}{l}\text { Long lead times for water management } \\
\text { engineering, projects and installations }\end{array}$ & $\begin{array}{l}\text { Ground failure, slope instability, } \\
\text { inrush }\end{array}$ \\
\hline \multirow[t]{2}{*}{$\begin{array}{l}\text { Environmental and } \\
\text { climate change }\end{array}$} & $\begin{array}{l}\text { Poor design or integration of drainage } \\
\text { infrastructure, pumping equipment and } \\
\text { pipelines into production and operational } \\
\text { plans and schedules }\end{array}$ & $\begin{array}{l}\text { Water management impacts the } \\
\text { environmental, water resources } \\
\text { and surrounding community } \\
\text { Increase cost of regulatory } \\
\text { compliance }\end{array}$ \\
\hline & $\begin{array}{l}\text { Operational teams do not have the training, } \\
\text { resources, technical or management support } \\
\text { to deliver the dewatering targets or } \\
\text { diversions }\end{array}$ & $\begin{array}{l}\text { Failure to secure licences and } \\
\text { permits }\end{array}$ \\
\hline
\end{tabular}

As the risks and commodities are varied, so are the controls to manage them. At BHP, we use controls to reduce the likelihood and/or impact in managing the causes of the risk event and a mitigating control that will reduce the impacts which flow from a risk. To manage the risks related to slope management, we therefore need multidisciplinary technical controls at the corporate, planning and operational levels of the business.

BHP's corporate controls are a series of technical standards including the Geotechnical Standard and Water Management Standard.

The Water Management Standard is a corporate-wide document that recognises the importance of water management in production and safety. It outlines the basis of water management across BHP by considering a whole-of-asset approach, clarifying management objectives, and enabling timely controls based on risk appetite. The Water Management Standard includes all water-related activities in the value chain from exploration through the closure, including dewatering, depressurisation and pit void management as a key enabler for geotechnical design, engineering, cost reduction and safety. This risk control document seeks that each operation embeds water into their essential business process, plans and risk management.

In terms of planning and operational site-specific controls, there is a wide range of production and safety risks identified including the following two examples:

1. WAIO dewatering and surplus volumes: The ability to meet ore production and maintain slope stability targets has been increasingly reliant on dewatering and surplus water management (Figure 3). In WAIO, we have more than 20 below watertable ore bodies representing $30 \%$ of the total ore volume requiring approximately $200 \mathrm{ML} / \mathrm{d}$ to be pumped. The amount of water currently being pumped for dewatering purposes is two to three times greater than the site demand for material handling and other uses such as dust suppression. The management of this excess water presents a material risk if there is no sustainable option to manage the excess, the mine dewatering program can be constrained and consequently constrain the mine plan and increase the 
geotechnical risks. This mining district is also located in a semi-arid zone which experiences large cyclones. This creates greater geotechnical and operational risks due to the seasonal variation of the mine water balance, water levels and potentially transient pore pressure effects.

Water-related controls to manage this risk are multidisciplinary and can be grouped holistically as:

- Surface water-related controls, included wet weather mine plans.

- Hydrogeological-related controls, included in dewatering and surplus management plans.

- Geotechnical-related controls, included in ground control management plans.

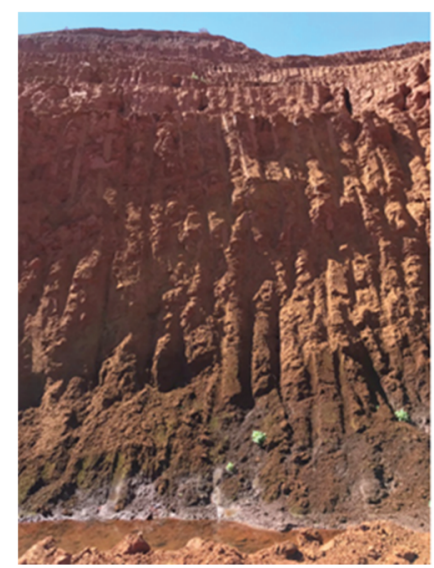

(a)

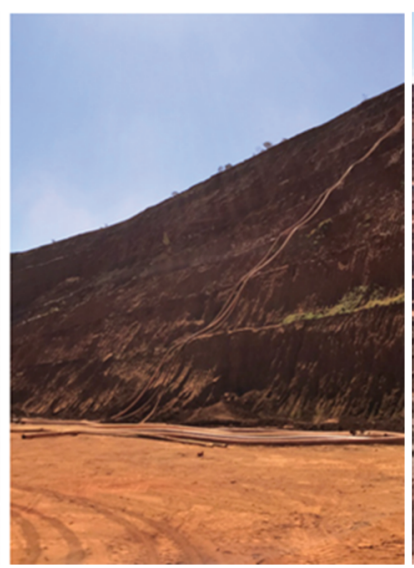

(b)

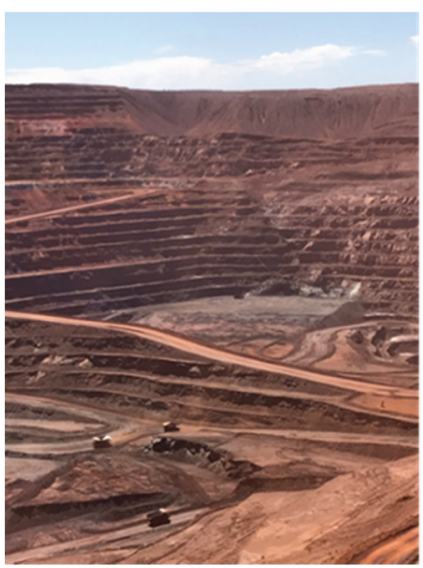

(c)

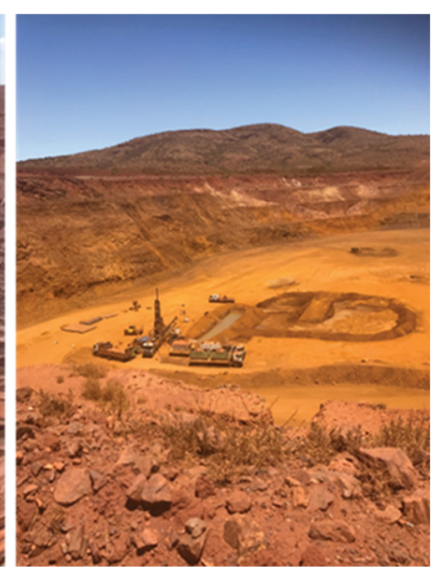

(d)

Figure 3 Dewatering in WAIO mines (a) Australia; (b) Mining Area C dewatering; (c) Whaleback ramp system; (d) Jimblebar OB31 pit

2. Pit void water management and variable climate: In our coal assets, primarily in Queensland and New South Wales, the water balance and production risks management focusses on changing and dynamic water conditions. We have around 22 operations and a number of projects and we are required to store and move approximately $150 \mathrm{GL}$ between pits to allow production optionality, to ensure water supply and control geotechnical risks. Water-related risks require BHP and other miners in the region to manage extreme drought to excessive flooding outcomes (depending on rainfall patterns over a 5-8 year cycle) resulting in production, operational and environmental impacts. There are many similarities between WAIO and our coal operations in terms of managing surplus water and potential geotechnical impacts, but also specific differences such as the complexity of some sites in surplus conditions while others are in shortage that constraints production. That's why we need to balance storage with water release. This issue requires additional risk controls definitions, beyond water management, geotechnical and wet weather plans, with a strong focus on water balance uncertainty analysis, TARPs and performance metrics definition according to hydrologic conditions, infrastructure design and implementation.

As a result, over several years, BHP Mitsubishi Alliance (BMA) in Queensland has invested in water infrastructure that enables pit dewatering through a water network between Caval Ridge, Peak Downs, Saraji and Norwich Park mine water storage systems to facilitate sustainable resilience to manage rainfall variability (Figure 4). 

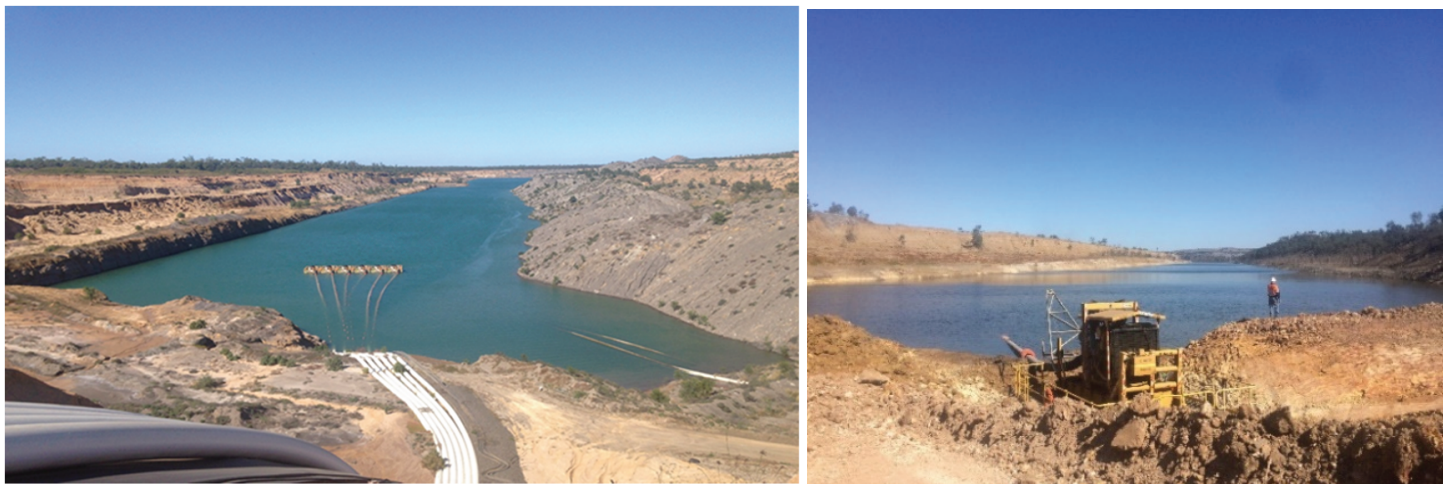

Figure 4 Water storage and pit void coal operations in Queensland, Australia

\subsection{Strategy, planning and operations}

The planning time frame for water management is long and complex. It is therefore critical to ensure mine water management is embedded in the planning process from an early stage. The extent and approach to planning and strategic direction in mine water management plays a significant role in the way we design and operate pits, especially where pore pressure or increased water levels are key drivers.

The BHP planning process is outlined in 'Our Requirements CAP' document which is the mandatory and, fundamental company-wide planning processes which is designed to maximise value by understanding strategic growth options and focus on medium and short-term plans.

Mine water management should be aligned with the corporate planning and capital process and organised in a Plan-Do-Check-Act (PDCA) across all planning, operations and closure management activities. Currently, if there is a water-related activity defined as a key enabler or a water-related material risk for the mine site, dewatering, depressurisation and pit void management plans need to be developed, implemented and maintained for all current and future mines operating below watertable. This is a minimum requirement as outlined in the BHP Water Management Standard.

This is the case of Escondida mine where dewatering and depressurisation is a water-related cause of ground failure material risk.

The Escondida mine site is a large open pit located in the Chilean Atacama desert. Pit slope pore pressures have become a critical water-related cause for geotechnical risks. Pore pressure and water presence, combined with the complexity of the geology, structural, hydrogeology and compartmentalised systems, play a fundamental role in defining the slope design and in mine planning. Recently, Escondida implemented a mine water planning approach that allows all mine dewatering and depressurisation plans to be developed in alignment with the mine planning process, geotechnical design and engineering process (Figure 5). 


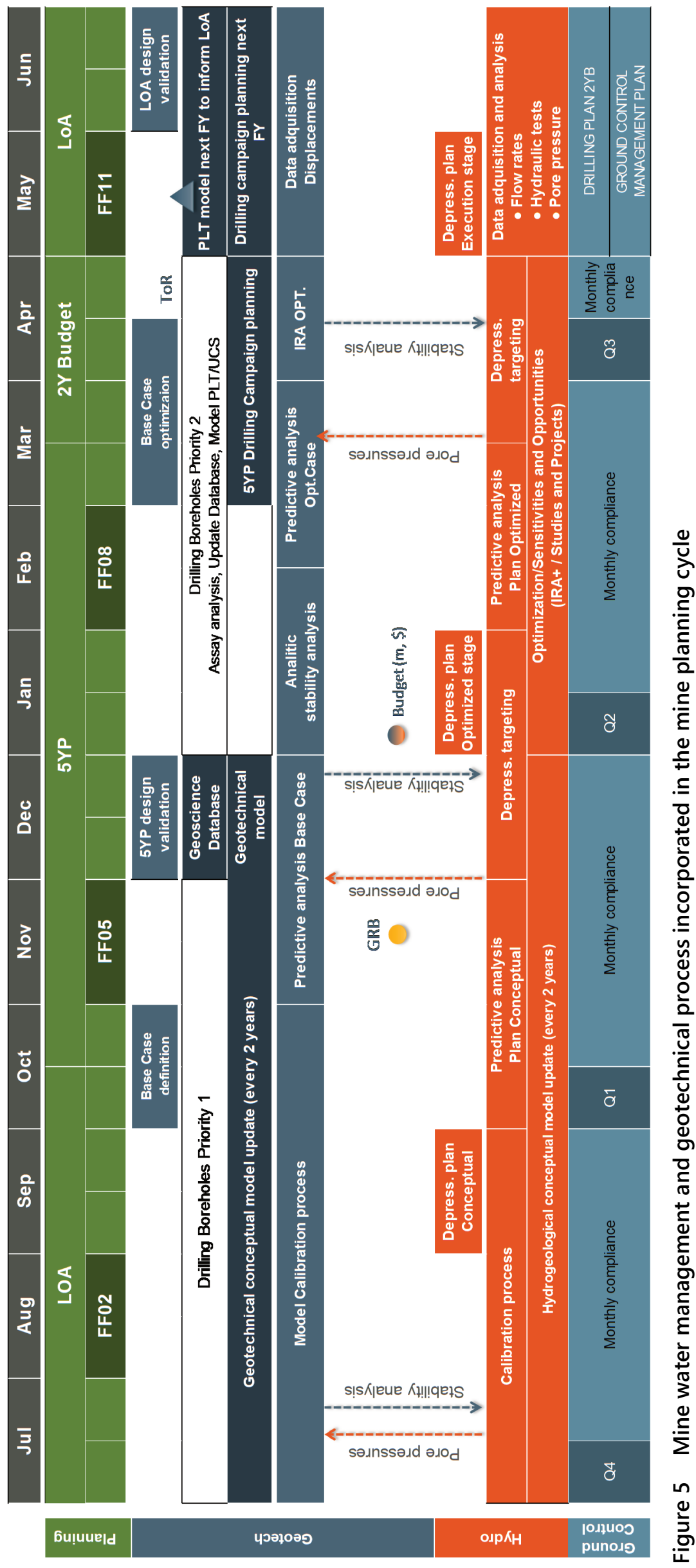


Including dewatering and depressurisation systems design criteria, dewatering lead times, operational performance targets, and operational and maintenance programs into the mine planning process is key. It is also critical to ensure risks and opportunities are communicated as part of the planning and geotechnical processes.

As part of dewatering and depressurisation plans more broadly in the business, each operation sets site-specific targets based on mine planning assumptions, hydrogeological conditions, operational conditions, geotechnical assumptions and potentially, environmental or water management constraints (e.g. disposal alternatives of surplus water generated from dewatering). This is fundamental to assess the effectiveness of our plans and review and adapt them, if required.

Dewatering operational performance targets could be established via:

- Proactive dewatering/depressurisation, pumping or remove to achieve water levels or reduce pore pressure to a pre-determined target in advance of mining, e.g. $12 \mathrm{~m}$ below the pit floor six months before mining or reduce absolute pore pressures by a percentage before a pushback commences.

- Pre-mining dewatering pumping time frame required to achieve the optimum in situ ore moisture content or dry operating conditions (including blasting).

- Proactive dewatering/depressurisation systems and operational performance $-80 \%$ availability of pumping wells and mine dewatering transport system.

Examples of the performance metrics for WAIO and Escondida are in Figures 6 and 7.
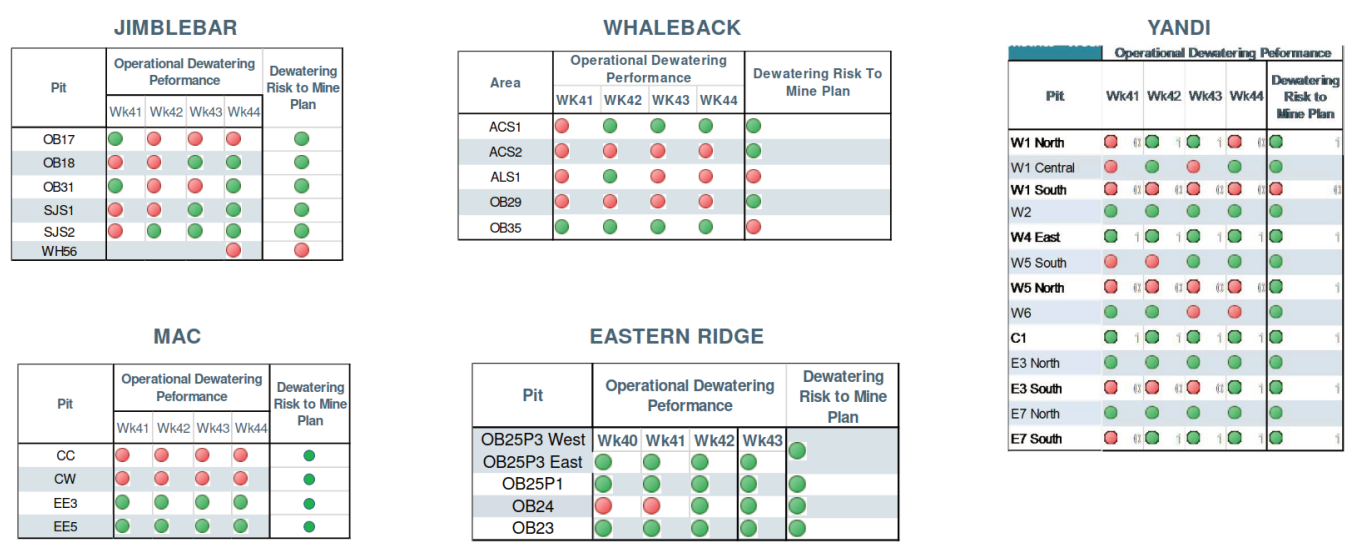

Figure 6 Example of how WAIO set performance some metrics and monitor compliance to plan
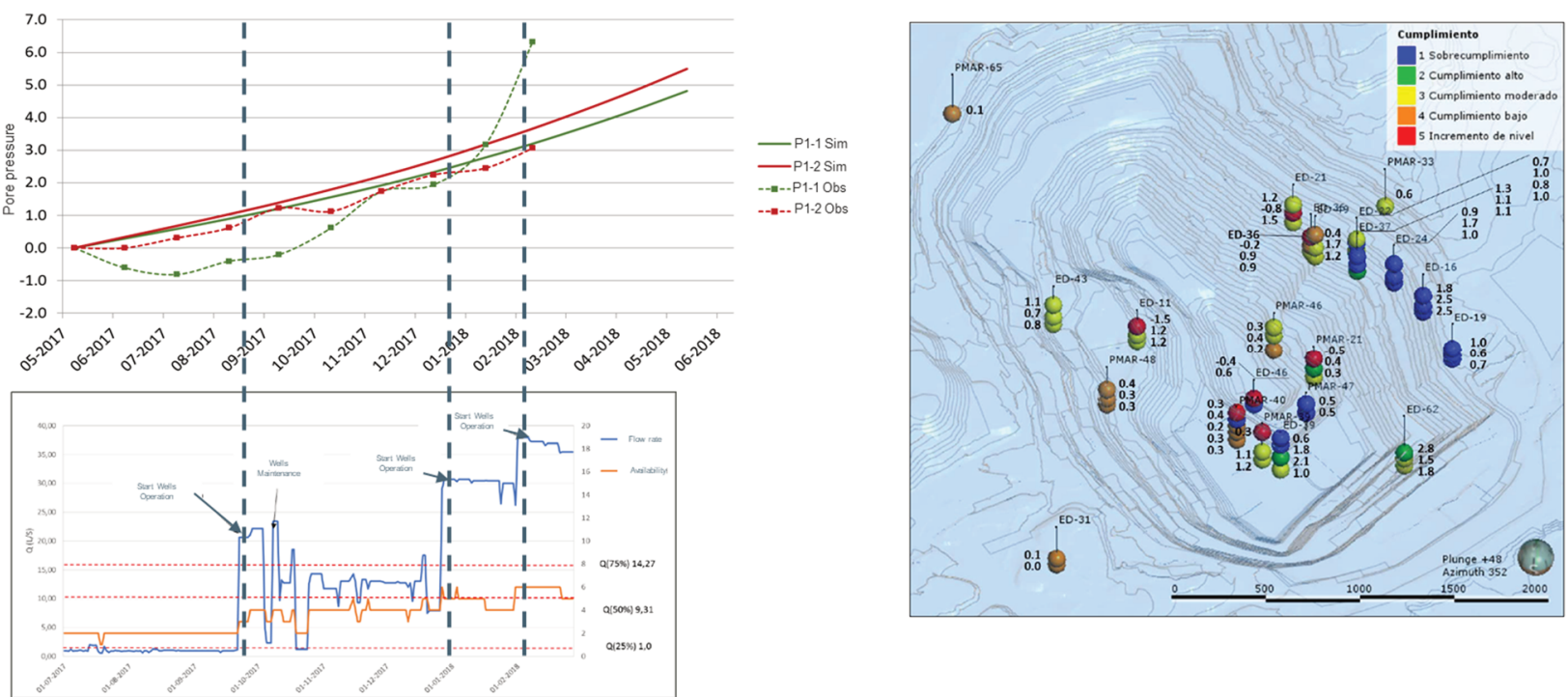

Figure 7 Example on how Escondida set performance metrics and monitor compliance to plan 


\subsection{Data and information}

Improving the quality of hydrogeological data and information that defines strategic, planning and operational decisions is another key focus for BHP. Water data management needs to address specific objectives to build knowledge that informs plans and decisions, operational performance, risk management and control effectiveness, regulatory and licence compliance. In terms of slope water management, the key drivers are to inform the proper hydrogeological data management, geotechnical mechanism of failure, hydrogeological modelling (conceptual and numerical), dewatering and depressurisation infrastructure systems and mine planning.

Over the past 28 years of operation, Escondida has drilled and constructed more than $50,000 \mathrm{~m}$ of horizontal drain holes, multiple in-pit and outpit pumping wells, monitoring wells and a 1,400 m tunnel to release pore pressures into the slopes (Figure 8). This complements the geological, geotechnical and structural information and has provided valuable data and information which has helped evolve the hydrogeological conceptualisation and pore pressure numerical modelling for business planning decision-making and informed geotechnical design.

Currently, the depressurisation focus is allowing significant pushbacks in the northeast and east wall to develop, such as PL1 pushback, and advancing depressurisation in the south-southeast wall to allow E6, E7 and S4 pushbacks. All systems are mainly target structures that have been identified as highly important for depressurisation controls or rock mass to lower pore pressure in risk areas of non-daylight wedges.

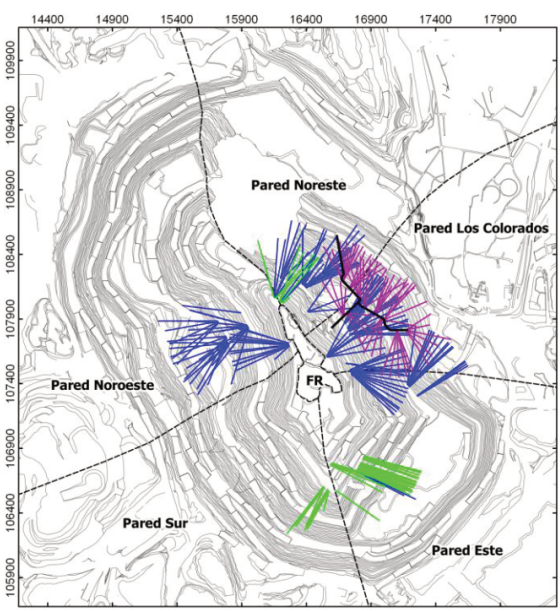

(a)

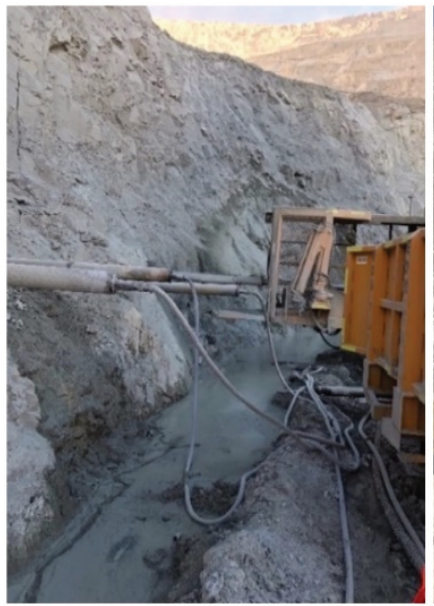

(c)

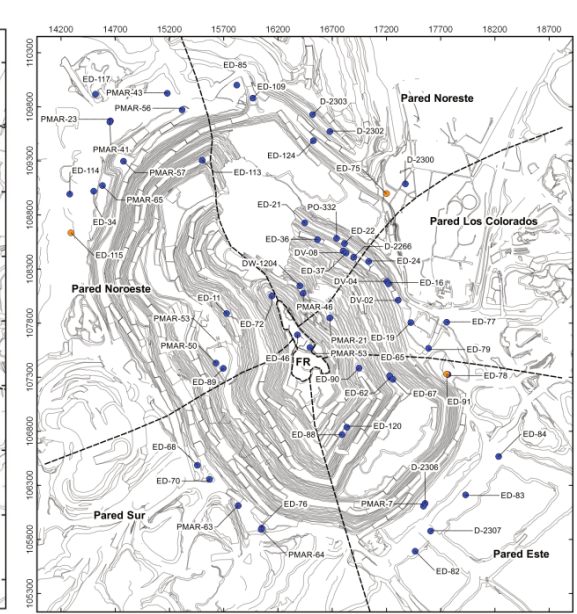

(b)

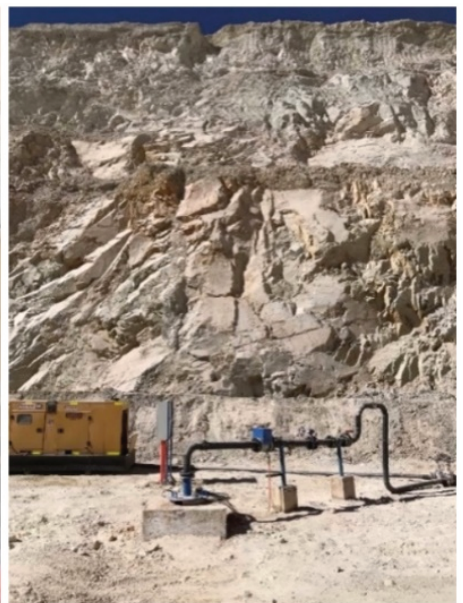

(d)

Figure 8 Dewatering and systems in Escondida pit mine, Chile. (a) General view of Escondida active drain holes; (b) Escondida active monitoring network; (c) Drain hole system; (d) Dewatering wells 
With efficient real-time monitoring, we have improved the effectiveness of our ground control. Through a monitoring network that includes vibrating wire piezometers and monitoring wells in strategic geotechnical locations behind the pit slopes, an additional layer of hydrogeological information is available (though not reviewed daily) to track and observe changes in stability and pore pressure controls. Escondida has also introduced improvements in the monitoring systems technology that has changed how we approach ground control. A new control room now features IBIS radar, Reutech radar, robotic total stations and prisms and piezometers (Figure 9).
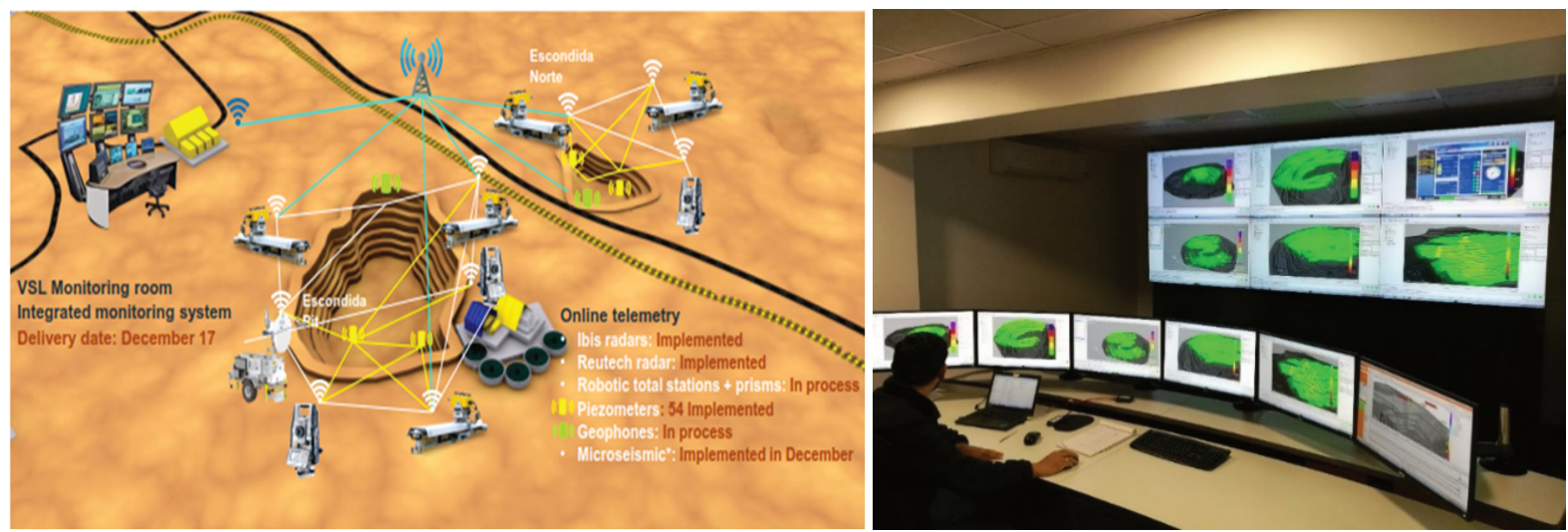

Figure 9 Ground control monitoring room (24/7), that include hydrogeological monitoring control

\subsection{Knowledge and uncertainty}

Integrating technical disciplines, such as hydrological and hydrogeological information, into conceptual and numerical predictions helps provide the technical basis of geotechnical designs and mine plans. Processes capture and improve the integration and linking of core geoscience and engineering aspects in the business plans and are a key focus for BHP. For example, by integrating geology, geophysics, structural geology, hydrogeology and hydrology, geotechnical engineering, and mine planning and closure, we have more opportunities to optimise mine slope, reduce safety risks, increase angle, optimise stope, reduce cost and optimise ground support. Figure 10 shows the links between geoscience and technical disciplines to improve the overall outcomes in design and risk management.
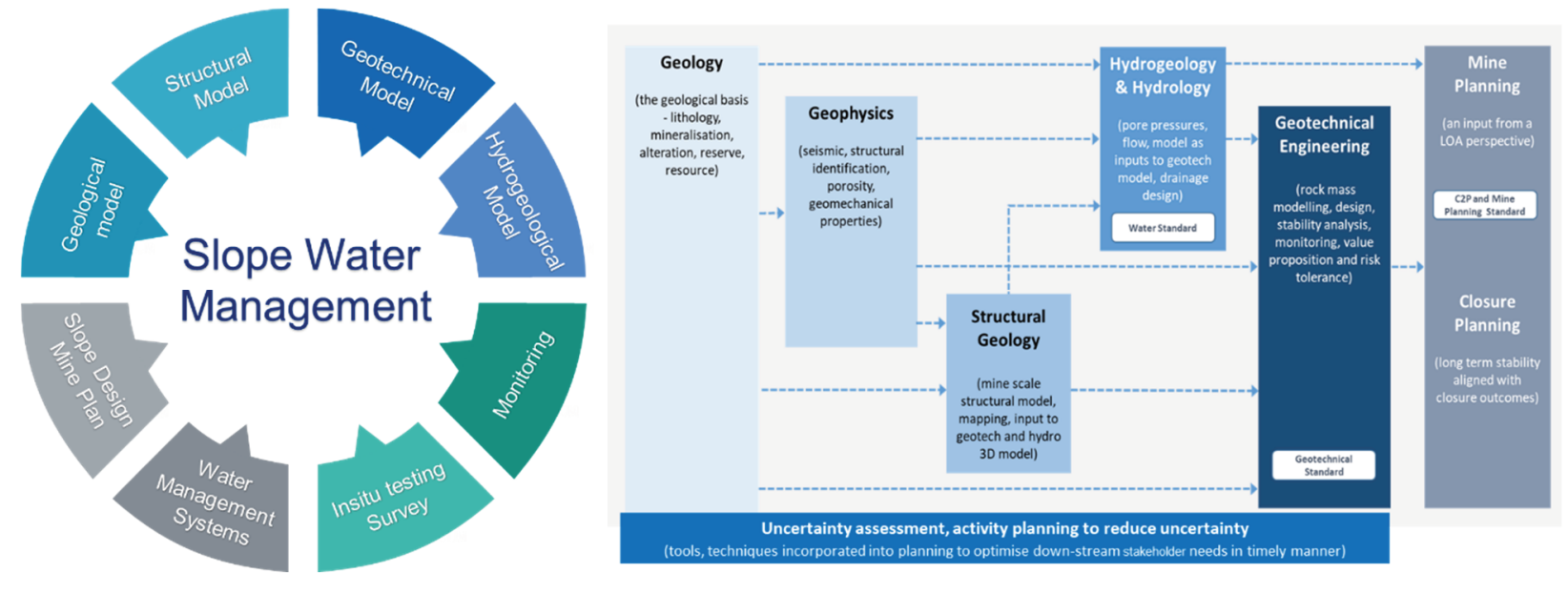

Figure 10 Integration of technical disciplines into slope water management and geotechnical design

As part of the planning process in Escondida and as shown in Figure 5, all relevant information for developing conceptual and numerical hydrogeological models that inform geotechnical designs are compiled, reviewed and integrated in-line with the planning cycle. The process of information integration can be understood, as shown in Figure 11. 

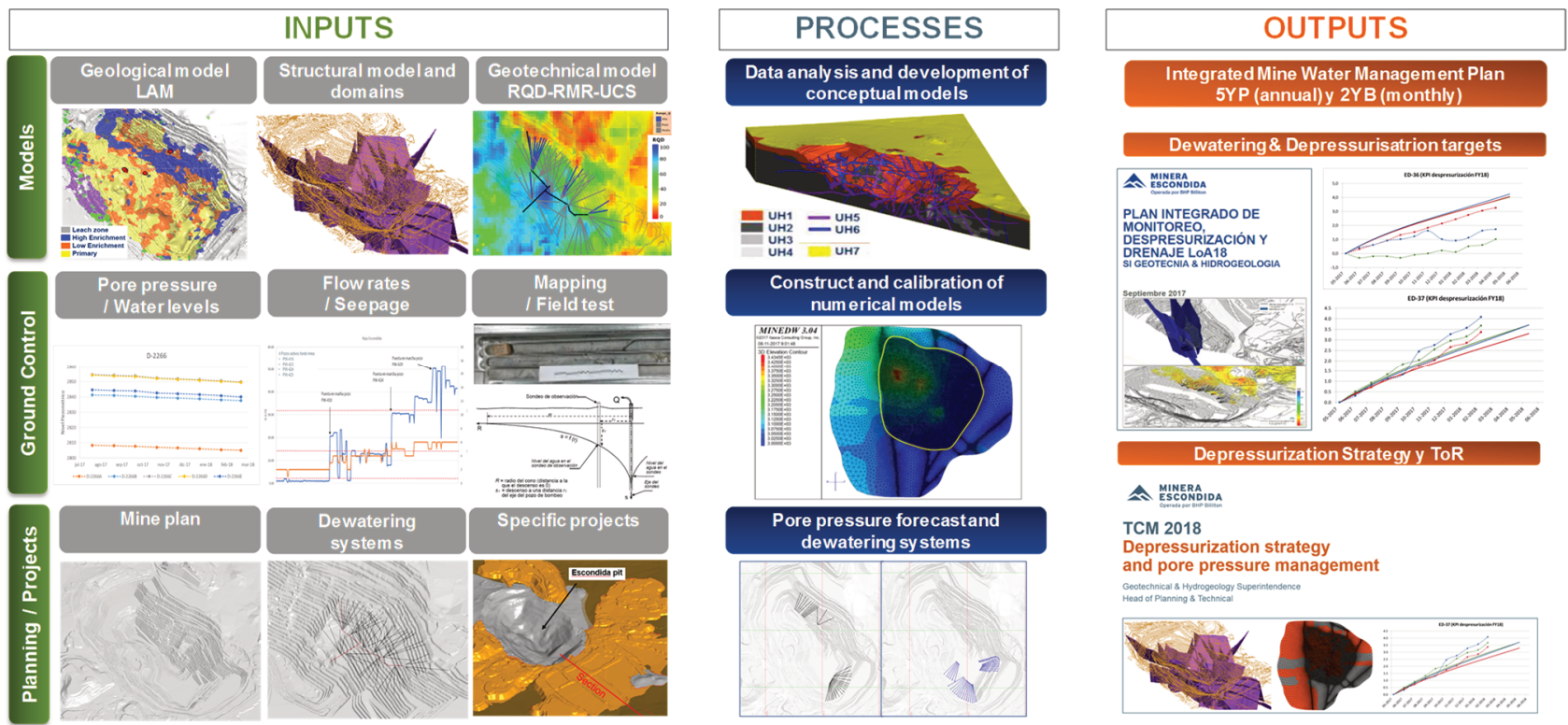

Figure 11 Escondida's conceptual mine water management process

Fundamental to prioritising the hydrogeological data and information required, and defining ad hoc triggers and thresholds for risk management, is an understanding of the mechanism of failure, the importance of pore pressure in the stability analysis, and an assessment of the full dimension of geotechnical risks. Escondida recognises the role that hydrogeological conditions play in influencing ground failure. Integrating hydrogeological mapping into geotechnical risks across the pit has allowed Escondida to revise and update drilling campaigns, operational plans and execution activities (Figure 12).

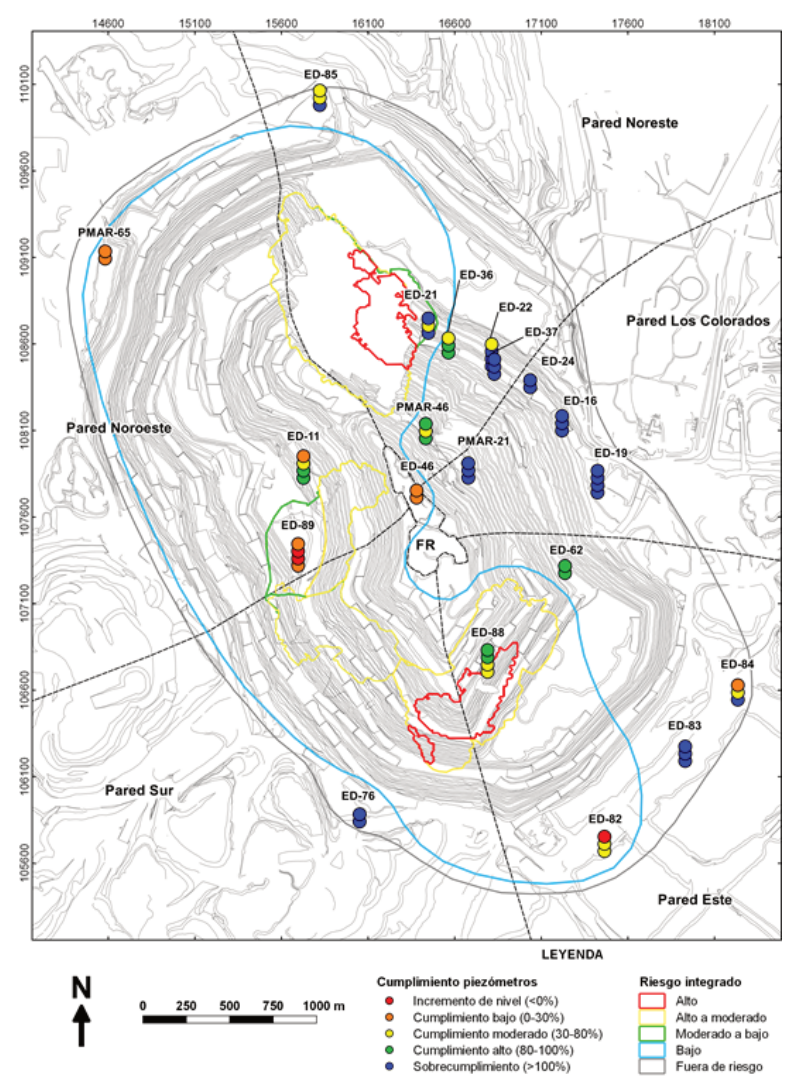

Figure 12 Example of Escondida sectorisation according hydrogeological and geotechnical information and risk level 


\section{Conclusion}

As a global organisation, we recognise the many challenges and opportunities that are faced in order to achieve adequate mine water management in slope stability and mine operations. This is not a challenge that is specific to BHP but is common across the industry. Ensuring we maintain focus and approach on the priority risks and production drivers is fundamental to making the right decisions, managing risk and optimising resource value. In summary, successful mine water management requires:

- A defined approach to mine water management which integrates mine planning, geotechnical, hydrogeological, water and business risk appetite to allow flexibility and changing mine plans. This will allow us to create awareness and define effective controls to manage water-related risks in the short and long-term.

- A well-defined strategic and operational mine water management approach that is developed and embedded into business objectives and CAP process ensuring informed water-related decisions can be made at the time required.

- A strong basis of hydrogeological and geotechnical characteristics, such as understanding the role of water in different mechanisms of failure that informs how pore pressure and water management will improve planning, design and operation of the slope water management.

- An understanding and preparedness for technical uncertainty and mine planning changes to ensure resource value is optimised as large pits deepen and more below watertable operations commence.

- A fundamental commitment to integrating and aligning technical disciplines to core business processes to improve the overall outcomes for slope water management.

\section{Acknowledgement}

The author thanks the Escondida geotechnical and hydrogeology team, coal water planning team and WAIO water planning team for their hard work and information provided.

\section{References}

International Organization for Standardization 2018, ISO 31000:2018 Risk Management - Guidelines, https://www.iso.org/ standard/65694.html 
